\title{
Vermifiltro: alternativa para tratamento de esgoto em sistemas descentralizados
}

\section{Vermifilter: alternative to sewage waste treatment in decentralized systems}

Data de entrada: 23/07/2019

Data de aprovação: 09/10/2019

Fábio Campos ${ }^{1}$ | Rodrigo de Freitas Bueno ${ }^{2}$ | Herica Tiepole Lee ${ }^{3}$ | Larisa Lika Narise ${ }^{3}$

DOI: https://doi.org/10.36659/dae.2020.089

ORCID ID

Campos F iD https://orcid.org/0000-0002-8117-789X

Bueno RF (iD https://orcid.org/0000-0002-6274-3278
Lee HT iD https://orcid.org/0000-0002-8475-0508

Narise LL (iD https://orcid.org/0000-0002-5683-4907

\section{Resumo}

Com o avanço nas pesquisas na área do Ecossaneamento, novos processos de tratamento começam a se mostrar promissores. Nesse sentido, o presente trabalho teve por objetivo avaliar o sistema de Vermifiltro; tal processo baseia-se no uso de reatores atuando como biofiltros aeróbios abrigando como material de enchimento substrato e uma população de minhocas detritívoras. Para este estudo foi construído e operado um sistema de vermifiltro seguido de dois leitos filtrantes: um contendo argila expandida, e outro, fibra de coco. Obtiveram-se resultados satisfatórios para remoção de sólidos em suspensão totais (média de 77\%) e para matéria orgânica (média de $81 \%$ em termos de DQQO), mas baixa e insignificante eficiência na retenção de fósforo (média de 37\%) e nitrogênio (média de 14\%), respectivamente. Por não apresentar demandas com o manejo de lodo ou podas de macrófitas, o processo de vermifiltração mostra-se interessante opção ao tratamento de esgoto no modelo descentralizado.

Palavras-chave: Tratamento descentralizado. Vermifiltro. Saneamento rural.

\section{Abstract}

With the advancement in research in the area of Eco-sanitation, new treatment processes are beginning to show promise. On this premise, the present study aimed to evaluate the Vermifilter system. This process is based on the use of reactors as aerobic biofilters housing as filling material substrate and a population of detritivoras worms. For this study a system of vermifilter followed by two filter beds, one containing expanded clay, and another, coconut fiber, was constructed and operated.It obtained satisfactory results for solids removal total suspension (average $77 \%$ ) and for organic matter (average of $81 \%$ in terms of COD), but low and negligible phosphorus retention efficiency (average 37\%) and nitrogen (average of $14 \%)$, respectively. By not presenting demands to the management of sludge or pruning of macrophytes, the process of vermifilter shows interesting option to sewage treatment in decentralized model.

Keywords: Decentralized system. Vermifilter. Eco-sanitation.

\footnotetext{
${ }^{1}$ Escola Politécnica da USP - São Paulo - São Paulo - Brasil.

2 Universidade Federal do ABC - Santo André - São Paulo - Brasil.

${ }^{3}$ Escola de Artes, Ciências e Humanidades da USP - São Paulo - São Paulo - Brasil.

*Autor correspondente: fcamposausp.br.
} 


\section{INTRODUÇÃO}

Em novembro de 2002, o CDESC (Comitê de Direitos Econômicos, Sociais e Culturais - ONU) adotou o Comentário Geral 15, que interpreta o Convênio Internacional ocorrido em 1966, confirmando o direito à água no Direito Universal (CDESC, 2003; ONU 2018). De acordo com o Comentário Geral 15 do CDESC, indivíduos ou grupos devem dispor de um acesso total e igualitário sobre informações referentes a águas e serviços de água e meio ambiente, sendo de direito participar nos processos de tomada de decisões que possam afetar suas atividades referentes a esse direito; entretanto, somente em julho de 2010 a ONU reconheceu formalmente, por meio da Resolução $n^{\circ}$ 64/292, o direito à água potável e limpa e o direito ao saneamento como essenciais para uma vida plena e para a concretização de todos os direitos humanos (ONU, 2010; ONU, 2014).

Em reforço ao direito de água potável e saneamento, foi proposto a criação de uma agenda internacional de desenvolvimento sustentável, a Agenda 2030, com 17 Objetivos de Desenvolvimento Sustentável (ODS) em setembro de 2015. Os países, que decidiram adotar os ODS possuem o dever de assegurar a disponibilidade e gestão sustentável de água e saneamento para todos até o ano de 2030 (BOS et al., 2016; PNUD, 2018).

O modelo de esgotamento centralizado adotado no Brasil ainda denota um privilégio na implantação de tratamento de esgoto para grandes cidades com bairros considerados prioritários e uma exclusão desse direito para populações com rendas mais baixas ou consideradas mais vulneráveis. Fato que se torna uma problemática diante do cenário de legislação e metas mundiais (OLIVEIRA JÚNIOR, 2013). Dessa forma, os sistemas de tratamento de esgoto centralizados não devem ser considerados como a única solução possível para o saneamento (OTTERPOHL; GROTTKER; LANGE, 1997), uma vez que impossibilitam a universalização ao dificultarem a chegada do tratamento de esgoto sanitário às comunidades menos favorecidas e/ou menos povoadas (OLIVEIRA JÚNIOR, 2013).

Como agravante a escolha e manutenção do modelo centralizado, pesa-se o fato de que tal não consegue atender aos requisitos de gestão sustentável, requisitos estes que estão se tornando cada vez mais necessários para uma boa perspectiva futura (SINHA; BHARAMBE; CHAUDHARI, 2008).

Sendo assim, torna-se necessário tanto a busca por tecnologias mais limpas que cumpram com os padrões de descarga de efluentes como a indispensabilidade de que tais tecnologias sejam implementadas de maneira efetiva nas regiões mais pobres economicamente e com predomínio de uma população mais vulnerável (SINGH; BHUNIA; DASH, 2017).

Diante desses cenários, dentre as opções tecnológicas que se configuram como solução descentralizada para o tratamento de águas residuárias em comunidades isoladas de menor porte e menor poder econômico, há a possibilidade do emprego de Vermifiltros (OLIVEIRA JÚNIOR, 2013).

Os Vermifiltros atuam, basicamente, como um filtro biológico aeróbio formado por uma camada superior de substrato contendo uma população de minhocas detritívoras da espécie Eisenia sp para o tratamento de esgoto doméstico, por meio do processo denominado vermifiltração. 0 primeiro trabalho publicado ocorreu em meados da década de 1990, sendo conduzido por pesquisadores da Universidade do Chile (MADRID, 2016; SUGIMOTO, 2016).

Analisando as potencialidades e vantagens acerca desse sistema de tratamento, constatou-se que, dentre as opções existentes até o momento, o processo de vermifiltração surge como alternativa de tratamento natural e operacional com grande eficiência no tratamento de esgoto, apresentando um desempenho equivalente na remoção dos 
poluentes em relação ao tratamento convencional, porém a um custo menor por conta da maior simplicidade na instalação e na manutenção uma vez que ele funciona como um filtro aeróbio que não gera lodo e não requer uso de energia, pois as minhocas ingerem todas as partículas suspensas presente no substrato e há uma aeração natural por meio de uma técnica denominada "burrowing action", ou seja, os túneis que as minhocas fazem para se locomover facilitam a circulação de ar em todas as camadas do meio (SINGH; BHUNIA; DASH, 2017; SUGIMOTO, 2016).

Segundo Kumar et al. (2014), as minhocas consomem a matéria orgânica e os sólidos presentes no esgoto degradando-os e transformando-os em vermicomposto, o qual pode usado como adubo orgânico por conta da concentração ideal de nitrogênio e fósforo presente. Contudo, os autores enfatizam que o efluente produzido ao fim do tratamento possui maior concentração de nitrogênio e fósforo, necessitando de materiais adsorventes para remover essas substâncias.

Sendo assim, o processo de vermifiltração tem dois grandes componentes centrais que auxiliam na remoção de poluentes: o substrato empregado e as minhocas. 0 substrato, além de ser uma fonte de alimento para as minhocas, proporciona um ambiente favorável para o crescimento e a reprodução de microrganismos (ZHAO et al., 2010).

As minhocas ingerem as partículas de solo e de poluentes que foram inseridos pelas águas residuárias. Os materiais consumidos recebem muco, enzimas e cálcio pela faringe e papo, sendo triturados e alterando suas propriedades físicas, químicas e biológicas; ao serem excretados, contribuem para a melhoria das atividades microbianas no substrato (SINGH; BHUNIA; DASH, 2017; SUGIMOTO, 2016).

Segundo Sinha, Bharambe e Chaudhari (2008), o próprio corpo das minhocas funciona como um biofiltro, podendo remover entre 90 e $92 \%$ dos sólidos dissolvidos totais, de 90 a $95 \%$ de sólidos totais em suspensão, $90 \%$ da DBO5,20 e de 80 a 90\% da DOQO, apenas pelo processo de digestão, além de suportarem ambientes com intervalos de $\mathrm{pH}$ de 4 a 9.

Em relação ao substrato presente no leito filtrante, abaixo da camada de solo, os mais usuais são brita, areia e materiais adsorventes.

Como material adsorvente, o carvão ativado é utilizado em grande escala para a purificação da água. O primeiro registro do uso desse material com a finalidade de tratar águas foi encontrado em meados dos anos de 1910 para remoção de cloro em Reading, Inglaterra (DONATI et al., 1994; MASSCHELEIN, 1992). Outro material empregado como adsorvente, sobretudo na remoção de nitrogênio e fósforo, é a cinza de carvão, sendo um resíduo inorgânico produzido pela queima do carvão, caracterizado como relativamente grosseiro e com partículas de 0,1 a 10 milímetros; possui em sua composição ferro, cálcio e alumínio, que constitui uma característica favorável para a adsorção dos nutrientes mencionados, além de outras substâncias, como magnésio, potássio, sódio, entre outros, que variam dependendo da fonte do carvão e das condições de queima a qual foi submetido (YANG et al., 2009).

Estudo realizado por Lo Monaco et al. (2009) utilizou fibras de cocos, que ficaram expostas ao sol durante três dias para a secagem e retirada de umidade sendo, em seguida, trituradas para atingir diâmetros entre 4 a 8 milímetros e empregadas como materiais adsorventes para o tratamento de águas residuárias de suinocultura. No experimento de Madrid (2016) foi empregado um filtro anaeróbio, para pré-tratamento do efluente, composto por partes iguais em forma de concha de casca de coco verde da espécie Cocos nucifera. Tais cascas serviam como "substrato fixador do biofilme que promovia a degradação anaeróbia da matéria orgânica" (MADRID, 2016). 
Diante dos fatores e condições operacionais que afetam a vermifiltração, a Tabela 1 apresenta al-

\begin{abstract}
guns trabalhos, evidenciando as características que cada autor escolheu em seus experimentos.
\end{abstract}

Tabela 1 - Características dos vermifiltros apresentados em diversos estudos

\begin{tabular}{|c|c|c|c|}
\hline Características & Soto \& Tohá, 1998 & Taylor et al., 2003 & Sinha et al., 2008 \\
\hline Camadas (do topo para o fundo) & $\begin{array}{l}\text { - De } 10 \text { a } 20 \text { cm de húmus com } \\
\text { minhocas; } \\
\text { - Camadas em sequência de } \\
\text { serragem, pedrisco e brita } \\
\text { (Detalhes não informados). }\end{array}$ & $\begin{array}{c}\text { - } 10 \mathrm{~cm} \text { coluna de } \\
\text { vermicompostagem; } \\
\text { - Leito filtrante com } 50 \mathrm{~cm} \text { de } \\
\text { profundidade } \\
\text { (Detalhes não informados). }\end{array}$ & $\begin{array}{l}\text { - } 10 \mathrm{~cm} \text { de solo de jardim puro com } \\
\text { minhocas; - } 20 \mathrm{~cm} \text { de agregados } \\
\text { (diâmetro de } 10 \text { a } 12 \mathrm{~mm} \text { ) } \\
\text { misturados com areia; } \\
-25 \mathrm{~cm} \text { de agregados } \\
\text { (diâmetro de } 35 \text { a } 45 \mathrm{~mm} \text { ); } \\
-25 \mathrm{~cm} \text { de brita } \\
\text { (diâmetro de } 75 \mathrm{~mm} \text { ). }\end{array}$ \\
\hline Temperatura durante operação & Não informada. & Não informada. & Mantida a $21,5^{\circ} \mathrm{C}$ \\
\hline $\mathrm{TDH}$ & Não informado. & Não informado. & De 1 a 2 horas \\
\hline TAS & $1.000 \mathrm{~L} / \mathrm{m}^{2} . \mathrm{d}$ & $130 \mathrm{~L} / \mathrm{m}^{2} . \mathrm{d}$ & Não informado. \\
\hline Período de análise & 2 anos. & 10 semanas. & 14 semanas. \\
\hline $\begin{array}{l}\text { Características do afluente aplicado } \\
\text { ao vermifiltro }\end{array}$ & $\begin{array}{l}\text { Apenas foi informada a faixa de } \\
\text { valores de DBO: de } 200 \text { a } 300 \text { mg/L. }\end{array}$ & Não informada. & Não informada. \\
\hline \multirow[t]{2}{*}{ Resultados / eficiência do vermifiltro } & $\begin{array}{c}\text { Remoção média de DBO } \\
\text { de } 91,2 \pm 4,1 \% \\
\text { SST de } 90 \pm 4,4 \% \\
\text { SSV de } 89 \pm 5,4 \% \\
\text { N de } 71 \pm 9 \% \\
\text { P de } 62 \pm 8.4 \%\end{array}$ & $\begin{array}{c}\text { Redução de DBO e DQO tão eficiente } \\
\text { quanto de ST - valores pelo menos na } \\
\text { faixa de } 70 \text { a } 80 \%\end{array}$ & $\begin{array}{l}\text { Remoção: acima de } 98 \% \text { de DBO; } \\
\text { acima de } 45 \% \text { de DQO; } \\
\text { acima de } 90 \% \text { SST; } \\
\text { acima de } 98 \% \text { de turbidez. }\end{array}$ \\
\hline & Li et al., 2009 & Xing et al., 2010 & Sartori, 2010 \\
\hline Camadas (do topo para o fundo) & $\begin{array}{l}\text { - } 30 \mathrm{~cm} \text { de mistura de palha, pó de } \\
\text { serra fina e grama com minhocas; } \\
\text { - } 40 \mathrm{~cm} \text { de palha e pó de serra; } \\
\text { - } 20 \mathrm{~cm} \text { de areia de quartzo fina } \\
\text { (diâmetro de } 10 \text { a } 15 \mathrm{~mm} \text { ); } \\
\text { - } 10 \mathrm{~cm} \text { de areia de quartzo grossa } \\
\text { (diâmetro de } 20 \text { a } 40 \mathrm{~mm} \text { ). }\end{array}$ & $\begin{array}{c}\text { - } 20 \text { cm de "areia cerâmica", } \\
\text { ou seja areia de fundição artificial } \\
\text { feita na China } \\
\text { (diâmetro de } 3,0 \text { a } 5,0 \text { mm) e areia de } \\
\text { quartzo (diâmetro de } 1,4 \text { a 2,36 mm) } \\
\text { com minhocas; } \\
\text { - } 10 \text { cm de areia de quartzo } \\
\text { (diâmetro de } 1,4 \text { a } 1,65 \text { mm); } \\
\text { - Tanque de sedimentação de lodo. }\end{array}$ & $\begin{array}{c}\text { - } 60 \text { cm de material orgânico (bagaço } \\
\text { de cana- de-açúcar serragem lixo } \\
\text { orgânico domiciliar compostado), } \\
\text { onde foram adicionadas } \\
\text { as minhocas; } \\
\text { - } 20 \text { cm de brita } 1 \text { para drenagem. }\end{array}$ \\
\hline Temperatura durante operação & $\begin{array}{l}\text { Sem controle de temperatura, sendo } \\
\text { registrado } 35^{\circ} \mathrm{C} \text { no dia mais quente. }\end{array}$ & $\begin{array}{l}\text { Sem controle de temperatura, sendo } \\
\text { registrados valores de } 22 \text { a } 34^{\circ} \mathrm{C} \text {. }\end{array}$ & Sem controle de temperatura. \\
\hline $\mathrm{TDH}$ & Não informado. & Não informado. & Não informado. \\
\hline TAS & De 1.500 a $3.000 \mathrm{~L} / \mathrm{m}^{2} . \mathrm{d}$ & De 2.400 a $6.000 \mathrm{~L} / \mathrm{m}^{2} . \mathrm{d}$ & De $500,1.000$ e $1.500 \mathrm{~L} / \mathrm{m} 2 . \mathrm{d}$ \\
\hline Período de análise & 1 ano. & 4 meses. & 5 meses. \\
\hline $\begin{array}{l}\text { Características do afluente aplicado } \\
\text { ao vermifiltro }\end{array}$ & $\begin{array}{c}\text { Valores médios: DBO } \\
\text { de } 159,7 \pm 40,2 \mathrm{mg} / \mathrm{L} ; \\
\text { DQO de } 323,7 \pm 79,5 \mathrm{mg} / \mathrm{L} ; \\
\text { SST de } 188,8 \pm 75,2 \mathrm{mg} / \mathrm{L} ; \\
\text { N Total de } 60,5 \pm 10,7 \mathrm{mg} / \mathrm{L} ; \\
\text { P Total de } 5,6 \pm 1,8 \mathrm{mg} / \mathrm{L}\end{array}$ & $\begin{array}{c}\text { Faixa de valores: } \\
\text { DBO de } 14 \text { a } 44 \text { mg/L; } \\
\text { DQO de } 42 \text { a } 100 \text { mg/L; } \\
\text { SST de } 14 \text { a } 48 \text { mg/L; } \\
\mathrm{NH}_{4}^{+} \text {de } 6 \text { a } 29 \text { mg/L; } \\
\text { N Total de } 16 \text { a } 29 \text { mg/L. }\end{array}$ & $\begin{array}{c}\text { Faixa de valores: } \\
\text { Turbidez de } 29 \text { a } 70 \mathrm{uT} ; \\
\text { DBO de } 111 \text { a } 275 \mathrm{mg} / \mathrm{L} ; \\
\text { DQO de } 432 \text { a } 824 \text { mg/L; } \\
\text { SST de } 116 \text { a } 196 \mathrm{mg} / \mathrm{L} ; \\
\text { N Total de } 35,15 \text { a } 64,76 \mathrm{mg} / \mathrm{L} ; \\
\text { P Total de } 7,17 \text { a } 8,30 \mathrm{mg} / \mathrm{L}\end{array}$ \\
\hline \multirow[t]{2}{*}{ Resultados / eficiência do vermifiltro } & 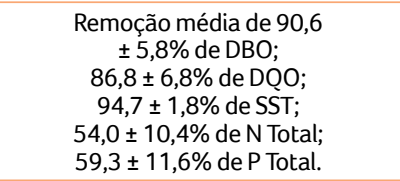 & $\begin{array}{c}\text { Remoção de } 54,78 \text { a } 60,89 \% \text { de } \mathrm{DBO} ; \\
\text { 47,26 a 57,55\% de DQO; } \\
\text { 62,06 a 77,9\% de } \mathrm{SST} ; \\
\text { 21,01 a.62,31\% de } \mathrm{NH}^{+} ; \\
\text {9,82 a } 11,9 \% \text { de } \mathrm{N} \text { total. }\end{array}$ & $\begin{array}{l}\text { Remoção de até: 91\% de turbidez; } \\
\text { 80\% de DBO; } \\
\text { 74\% de DQO; } \\
\text { 86\% de SST; } \\
\text { 74\% de N Total; 69\% de P Total. }\end{array}$ \\
\hline & Liu et al., 2013 & Nie et al., 2014a & Nie et al., 2014b \\
\hline Camadas (do topo para o fundo) & $\begin{array}{l}\text { - } 30 \text { cm de "areia cerâmica", ou seja, } \\
\text { areia de fundição artificial feita na } \\
\text { China (diâmetro de 3,0 a 5,0 mm); } \\
\text { - Tanque de sedimentação (o lodo é } \\
\text { posteriormente direcionado para um } \\
\text { leito de secagem). }\end{array}$ & $\begin{array}{c}\text { - } 40 \text { cm de serragem com solo } \\
\text { (proporção de } 3: 1 \text { em volume) } \\
\text { com minhocas; } \\
-20 \mathrm{~cm} \text { de areia } \\
\text { (diâmetro de } 0,2 \text { a } 2 \mathrm{~mm} \text { ); } \\
-10 \mathrm{~cm} \text { de brita } \\
\text { (diâmetro de } 2 \text { a } 10 \mathrm{~mm} \text { ); } \\
-20 \mathrm{~cm} \text { de brita } \\
\text { (diâmetro de } 15 \text { a } 30 \mathrm{~mm} \text { ); } \\
-30 \mathrm{~cm} \text { brita } \\
\text { (diâmetro de } 20 \text { a } 40 \mathrm{~mm} \text { ). }\end{array}$ & $\begin{array}{c}\text { - } 40 \text { cm de serragem com solo } \\
\text { (proporção de 3:1 em volume) } \\
\text { com minhocas; } \\
-10 \text { cm de areia } \\
\text { (diâmetro de 0,2 a } 2 \text { mm); } \\
-5 \text { cm debrita } \\
\text { (diâmetro de } 2 \text { a } 10 \text { mm); } \\
\text { - } 30 \text { cm de "areia cerâmica", ou seja, } \\
\text { areia de fundição artificial feita na } \\
\text { China - (diâmetro de } 20 \text { a } 30 \text { mm); } \\
-15 \text { cm brita } \\
\text { (diâmetro de } 20 \text { a } 40 \text { mm). }\end{array}$ \\
\hline
\end{tabular}

continua... 
Tabela 1 - Continuação...

\begin{tabular}{|c|c|c|c|}
\hline Características & Liu et al., 2013 & Nie et al., 2014a & Nie et al., 2014b \\
\hline Camadas (do topo para o fundo) & $\begin{array}{l}\text { - } 30 \text { cm de "areia cerâmica", ou seja, } \\
\text { areia de fundição artificial feita na } \\
\text { China (diâmetro de 3,0 a 5,0 mm); } \\
\text { - Tanque de sedimentação (o lodo é } \\
\text { posteriormente direcionado para um } \\
\text { leito de secagem). }\end{array}$ & $\begin{array}{c}\text { - } 40 \text { cm de serragem com solo } \\
\text { (proporção de } 3: 1 \text { em volume) } \\
\text { com minhocas; } \\
\text { - } 20 \text { cm de areia } \\
\text { (diâmetro de } 0,2 \text { a } 2 \mathrm{~mm} \text { ); } \\
\text { - } 10 \mathrm{~cm} \text { de brita } \\
\text { (diâmetro de } 2 \text { a } 10 \mathrm{~mm} \text { ); } \\
\text { - } 20 \mathrm{~cm} \text { de brita } \\
\text { (diâmetro de } 15 \text { a } 30 \mathrm{~mm} \text { ); } \\
\text { - } 30 \mathrm{~cm} \text { brita } \\
\text { (diâmetro de } 20 \text { a } 40 \mathrm{~mm} \text { ). }\end{array}$ & $\begin{array}{c}\text { - } 40 \text { cm de serragem com solo } \\
\text { (proporção de 3:1 em volume) } \\
\text { com minhocas; } \\
-10 \text { cm de areia } \\
\text { (diâmetro de 0,2 a } 2 \mathrm{~mm} \text { ); } \\
-5 \mathrm{~cm} \text { debrita } \\
\text { (diâmetro de } 2 \text { a } 10 \mathrm{~mm} \text { ); } \\
\text { - } 30 \text { cm de "areia cerâmica", ou seja, } \\
\text { areia de fundição artificial feita na } \\
\text { China - (diâmetro de } 20 \text { a } 30 \text { mm); } \\
-15 \text { cm brita } \\
\text { (diâmetro de } 20 \text { a } 40 \mathrm{~mm} \text { ). }\end{array}$ \\
\hline Temperatura durante operação & $\begin{array}{l}\text { Sem controle de temperatura, sendo } \\
\text { registrado valores de } 5,2 \text { a } 33,9^{\circ} \mathrm{C} \text {. }\end{array}$ & Sem controle de temperatura. & Sem controle de temperatura. \\
\hline $\mathrm{TDH}$ & Não informado. & Não informado. & Não informado. \\
\hline TAS & De 4.000 a $4.800 \mathrm{~L} / \mathrm{m}^{2} . \mathrm{d}$ & $1.000 \mathrm{~L} / \mathrm{m}^{2} . \mathrm{d}$ & $1.000 \mathrm{~L} / \mathrm{m}^{2} . \mathrm{d}$ \\
\hline Período de análise & 21 meses. & 10 meses. & 5 meses. \\
\hline $\begin{array}{c}\text { Características do afluente aplicado } \\
\text { ao vermifiltro }\end{array}$ & Não informadas. & Não informadas. & Não informadas. \\
\hline \multirow[t]{2}{*}{ Resultados / eficiência do vermifiltro } & $\begin{array}{l}\text { Valores médios de remoção: } \\
\text { 78,0 } \pm 14,1 \% \mathrm{mg} / \mathrm{L} \text { de DBO; } \\
67,6 \pm 8,3 \% \mathrm{mg} / \mathrm{L} \text { de DQO; } \\
89,8 \pm 4,1 \% \mathrm{mg} / \mathrm{L} \text { de } \mathrm{SST} \\
92,1 \pm 5,7 \% \mathrm{de} \mathrm{NH}_{4}^{+}\end{array}$ & $\begin{array}{c}\text { Faixa de valores: } \\
\text { DQO de } 20 \text { a } 125 \text { mg/L; } \\
\mathrm{NH}_{4}^{+} \text {de } 5 \text { a } 55 \text { mg/L; } N \text { total de } 15 \text { a } \\
75 \text { mg/L; P Total de } 2 \text { a } 6,5 \text { mg/L }\end{array}$ & $\begin{array}{l}\text { Remoção de em torno de } \\
\text { 80\% de DQO e } \mathrm{NH}_{4}^{+} ; \\
\text {N Total entre } 30 \text { e } 70 \% \\
\text { P Total entre } 50 \text { e } 90 \%\end{array}$ \\
\hline & Kumar et al., 2014 & Arora et al., 2014 & \\
\hline Camadas (do topo para o fundo) & $\begin{array}{c}\text { - } 5 \text { cm de substrato (vermicomposto } \\
\text { maduro); } \\
-10 \mathrm{~cm} \text { seixo rolado } \\
\text { (diâmetro de } 6 \text { a } 8 \mathrm{~mm} \text { ); } \\
-5 \mathrm{~cm} \text { seixo rolado } \\
\text { (diâmetro de } 1 \text { a } 2 \mathrm{~mm} \text { ); } \\
-5 \mathrm{~cm} \text { seixo rolado } \\
\text { (diâmetro de } 10 \text { a } 12,5 \mathrm{~mm} \text { ). }\end{array}$ & $\begin{array}{c}-20 \mathrm{~cm} \text { de substrato } \\
\text { (vermicomposto maduro); } \\
-15 \mathrm{~cm} \text { de areia } \\
\text { (diâmetro de } 1 \text { a } 2 \mathrm{~mm} \text { ); } \\
-15 \mathrm{~cm} \text { de cascalho } \\
\text { (diâmetro de } 6 \text { a } 8 \mathrm{~mm} \text { ); } \\
\text { - } 15 \mathrm{~cm} \text { de cascalho grosso e brita } \\
\text { (diâmetro de } 10 \text { a } 12 \mathrm{~mm} \text { ); } \\
\text { - } 15 \mathrm{~cm} \text { de espaço vazio para } \\
\text { aeração. }\end{array}$ & \\
\hline Temperatura durante operação & Sem controle de temperatura. & $\begin{array}{l}\text { Sem controle de temperatura, sendo } \\
\text { registrados valores de } 20 \text { a } 30^{\circ} \mathrm{C} \text {. }\end{array}$ & \\
\hline $\mathrm{TDH}$ & Não informado. & 7,8 horas. & \\
\hline TAS & De 1.500 a $3.000 \mathrm{~L} / \mathrm{m}^{2} . \mathrm{d}$ & $1.000 \mathrm{~L} / \mathrm{m}^{2} . \mathrm{d}$ & \\
\hline Período de análise & 90 dias. & 120 dias. & \\
\hline $\begin{array}{l}\text { Características do afluente aplicado } \\
\text { ao vermifiltro }\end{array}$ & $\begin{array}{l}\text { Valores médios: } \\
\text { DQO de } 472 \pm 18 \mathrm{mg} / \mathrm{L} ; \\
\text { DBO de } 327 \pm 13 \mathrm{mg} / \mathrm{L} ; \\
\text { SST de } 289 \pm 106 \mathrm{mg} / \mathrm{L} ; \\
\text { COT de } 210 \pm 18 \mathrm{mg} / \mathrm{L} ; \\
\mathrm{NH}_{4}^{+} \text {de } 20 \pm 2,5 \mathrm{mg} / \mathrm{L}\end{array}$ & $\begin{array}{c}\text { Valores médios: } \\
\text { DBO de } 242 \pm 30 \mathrm{mg} / \mathrm{L} ; \\
\text { DQO de } 456 \pm 32 \mathrm{mg} / \mathrm{L} ; \\
\text { Coliformes Totais de } \\
\text { 3,5* } 10^{8} \mathrm{MPN} / 100 \mathrm{~mL} \\
\text { Bactérias Heterotróficas de } \\
1,4 \times 10^{9} \mathrm{CFU} . \mathrm{mL}^{-1} \text {. }\end{array}$ & \\
\hline Resultados / eficiência do vermifiltro & $\begin{array}{c}\text { Valores médios: } \\
57 \pm 15 \mathrm{mg} / \mathrm{L} \text { de } \mathrm{DQO} \\
8 \pm 2 \mathrm{mg} / \mathrm{L} \text { de } \mathrm{DBO} \\
29 \pm 8,54 \mathrm{mg} / \mathrm{L} \text { de SST; } \\
30,5 \pm 1,83 \mathrm{mg} / \mathrm{L} \mathrm{de} \mathrm{COT} \\
2,7 \pm 0,42 \mathrm{mg} /{\mathrm{L} \mathrm{de} \mathrm{NH}_{4}^{+}}^{+}\end{array}$ & $\begin{array}{c}\text { Remoção média de } 92 \% \text { de DBO e } \\
74 \% \text { de DQO. } \\
\text { Valores finais de } 2,5^{*} 10^{5} \mathrm{MPN} / 100 \\
\mathrm{~mL} \text { de Coliformes Totais e } 2,0^{*} 10^{5} \\
\text { CFU/mL de Bactérias Heterotróficas. }\end{array}$ & \\
\hline
\end{tabular}

Fonte: Adaptado Madrid (2016)

Sendo assim, diante do exposto, o presente trabalho teve por premissa avaliar o emprego do sistema de Vermifiltro no que tange sua eficiência na remoção de sólidos, matéria orgânica e nutrientes.

\section{MATERIAL E MÉTODOS}

A pesquisa foi desenvolvida por meio de experimento em escala piloto, sendo posto em operação um sistema de tratamento de esgoto do tipo Vermifiltro, confeccionado em recipientes de polietileno 
de alta densidade (PEAD), mediante a introdução de conexões hidráulicas necessárias para aplicação e retirada do esgoto e efluente, respectivamente.

O experimento foi realizado em uma região de clima do tipo BSh (classificação de Köeppen e Geiger) com temperatura média de $24,4^{\circ} \mathrm{C}$ e pluviosidade média anual de $469 \mathrm{~mm}$ (ClimateData.org). Seu monitoramento iniciou-se em 18 de setembro de 2018, mantendo-se até 25 de junho de 2019, totalizando 281 dias de operação.

O esgoto sanitário que alimentou a unidade piloto era proveniente do Crusp Conjunto Residencial da Universidade de São Paulo -, sendo recal- cado para a área em que se encontrava a unidade piloto por meio de uma estação elevatória (EE), a qual consistia em um poço de sucção executado em concreto armado com duas bombas submersíveis operando intermitentemente. $\mathrm{Na}$ chegada do esgoto à área da pesquisa, o mesmo era submetido a um tratamento preliminar composto por peneiramento e desarenação, sendo em seguida encaminhado, por meio de uma calha parshall, até a caixa de gordura, e, por fim, para o poço de sucção de onde era derivado e acumulado em uma bombona de $200 \mathrm{~L}$, onde, por fim, era aplicado ao reator por meio de uma bomba peristáltica. A Fig. 1 ilustra o tratamento preliminar.
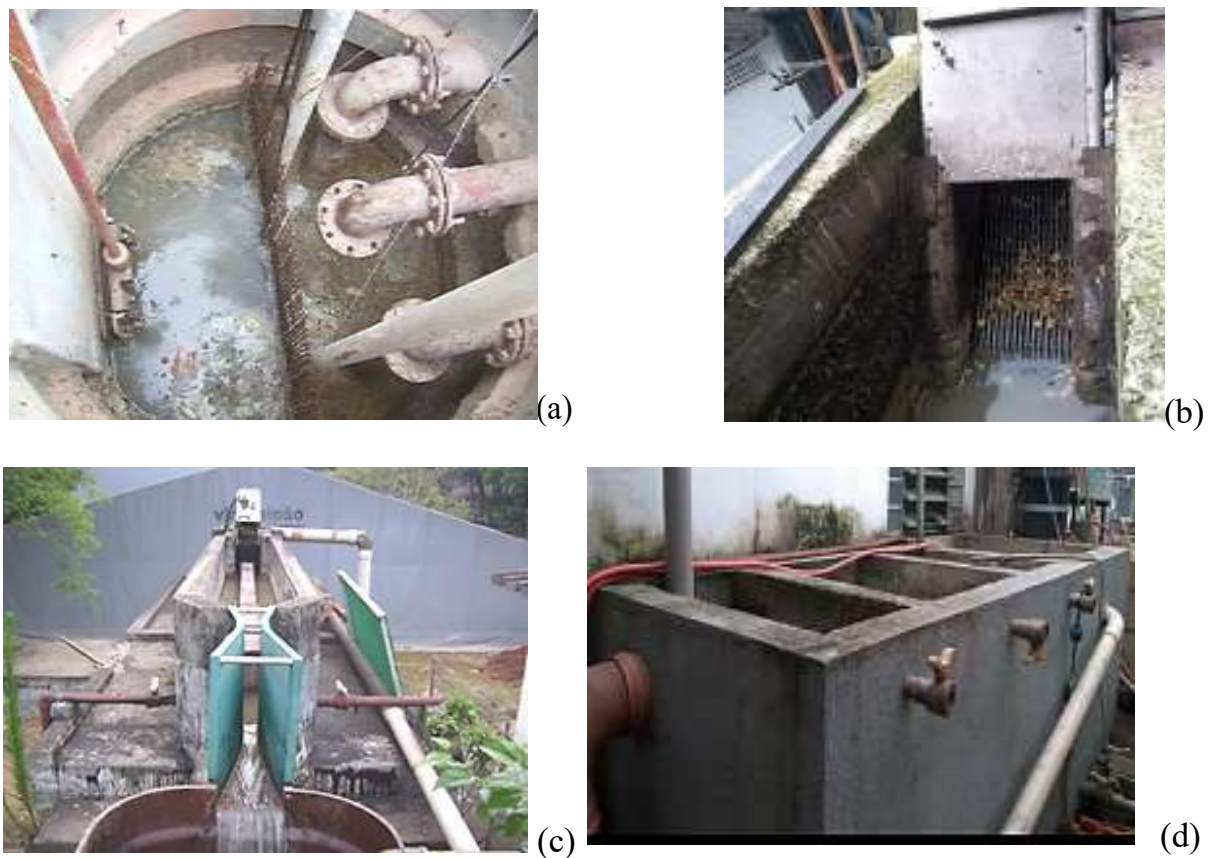

(d)

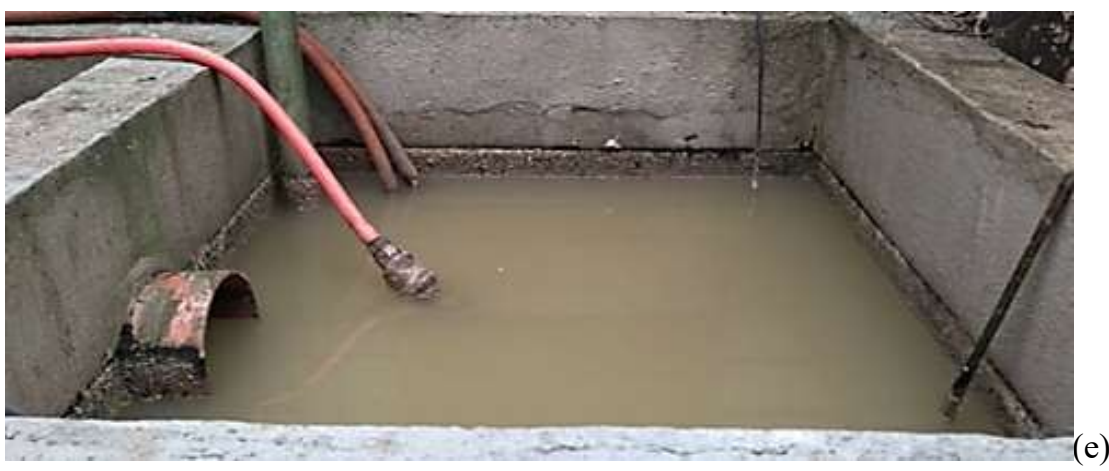

Figura 1 - Vista da EE e do Tratamento Preliminar. a - Elevatória de Esgoto; b - Peneira; c - Canal de Areia e Calha Parshall; d - Caixa de Gordura; e - Poço de Alimentação 
A unidade piloto de vermifiltro era formada por três reatores interligados e em série com as mesmas áreas e volume $\left(0,12 \mathrm{~m} 2\right.$ e 0,02 $\mathrm{m}^{3}$, cada), todos operando com fluxo sub-superficial vertical, sendo identificados de 1, 2 e 3 .

O Reator 1 operou como vermifiltro, sendo composto por uma camada de 4 centímetros de seixos (meio suporte para as conexões hidráulicas de saída de efluente), seguida de uma camada de 17 centímetros de brita (leito filtrante) e 14 centímetros de substrato (solo de floresta primária), onde foram alocadas as minhocas da espécie Eisenia sp, conhecidas popularmente como minhocas californianas; o número de minhocas utilizadas baseou-se no trabalho de Sartori (2010), onde o autor manteve a relação de 750 organismos por metro quadrado; sendo assim, trabalhou-se inicialmente com uma população de 90 minhocas. O fluxo sub-superficial vertical nesse reator não foi saturado para evitar o acúmulo de esgoto que poderia comprometer o hábitat das minhocas.

O Reator 2 operou como leito filtrante, sendo constituído pela camada de 4 centímetros de seixos como meio suporte, seguido de uma camada de 30 centímetros de argila expandida. 0 Reator 3 operou também como leito filtrante, sendo formado pelo mesmo meio suporte seguido de uma camada de 30 centímetros de fibra de coco. Ambos os reatores 2 e 3 operaram com o fluxo sub-superficial vertical saturado.

Com o propósito de evitar o alagamento do reator R1, buscou-se uma taxa de aplicação superficial (q) compatível com a área e a hidráulica do sistema; sendo assim, adotou-se o valor de 300 L/m2.dia, o que produzia uma vazão diária (Q) de $36 \mathrm{~L} / \mathrm{d}$, com uma relação habitante/área vermifiltro de $0,5 \mathrm{~m}^{2}$, o que torna o sistema bem compacto. O tempo de detenção hidráulico (TDH) decorrente desses parâmetros, para o reator R1, admitindo-se como teórico por não ser fluxo saturado, ficou em 13 horas; para os reatores R2 e R3, por possuírem um fluxo saturado, foi possível calcular o número de vazios e corrigir o volume dos mesmos, obtendo-se TDH de 7,7h e 12,1 h, respectivamente. Dessa forma, o sistema completo partiu com um TDH de 1,4 dia.

Para evitar proliferação de moscas ou outros insetos, foram colocadas telas na superfície dos reatores, ressaltando que o sistema foi instalado em área coberta, protegida de intempéries. A manutenção do sistema (renovação do esgoto afluente ao sistema, limpeza, ajuste de vazão) era feita diariamente.

A Fig. 2 ilustra o fluxograma operacional completo do sistema de vermifiltro, e a Fig. 3 apresenta a unidade piloto.

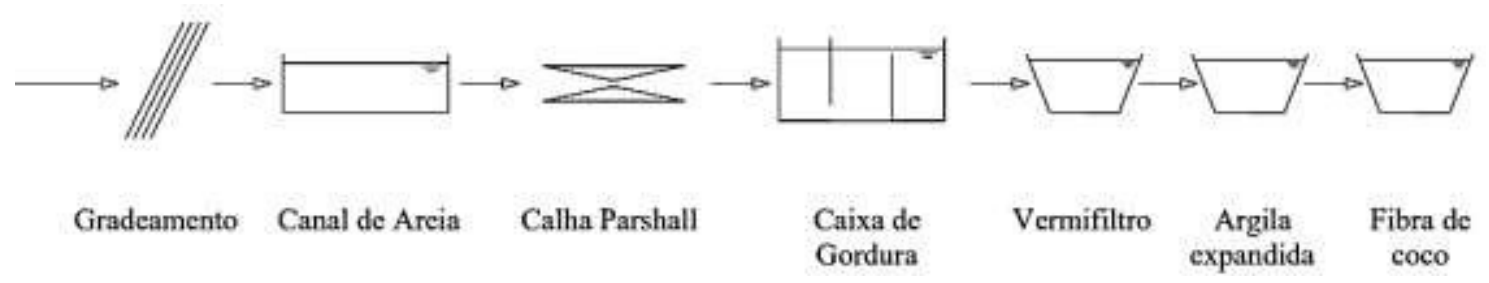

Figura 2 - Fluxograma operacional completo do vermifiltro 


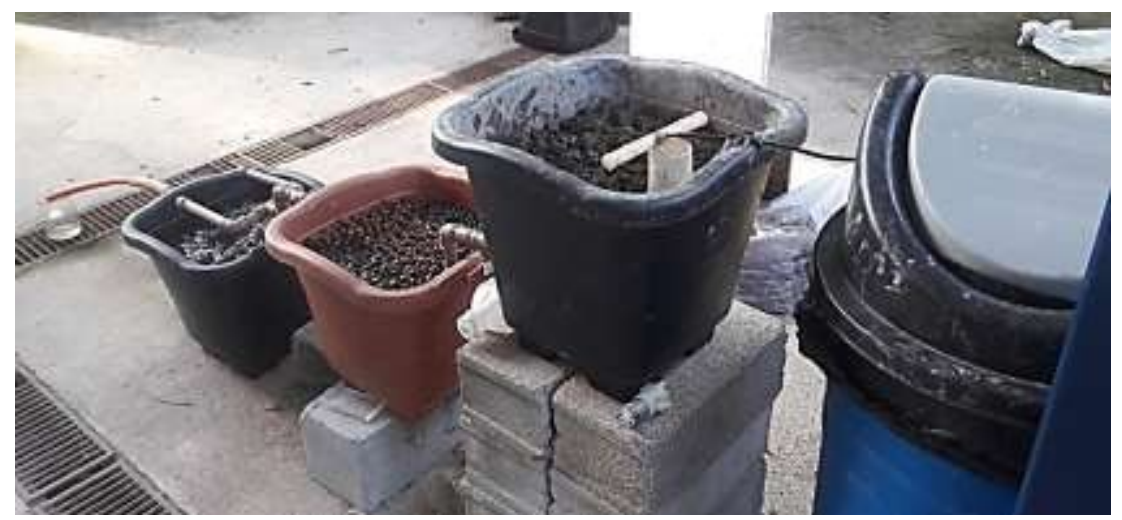

Figura 3 - Unidade piloto de vermifiltro

Tanto o esgoto como o efluente final (saída do R3) produzido pelo processo foram caracterizados duas vezes por semana por meio da determinação das variáveis Demanda Química de Oxigênio (DQO); série nitrogenada; fósforo total e ortofosfato solúvel; alcalinidade; $\mathrm{pH}$; sólidos em suspensão totais, fixos e voláteis (SST, SSF, SSV). As metodologias analíticas utilizadas seguiram a $21^{a}$ edição do Standard Methods for Examination of Water and Wastewater, da APHA / AWWA / WEF (2017).

A temperatura do substrato foi obtida simultaneamente com a amostragem para caracterização do esgoto/efluente, sendo anotada a temperatura do ar simultaneamente, bem como medidas de condutividades e $\mathrm{pH}$ semanalmente. Durante o experimento, houve a inspeção do comprimento de algumas minhocas escolhidas de maneira aleatória, bem como avaliação visual de sua mobilidade e vitalidade no substrato.

\section{RESULTADOS E DISCUSSÕES}

\subsection{Caracterização do esgoto e variáveis operacionais}

Em relação ao esgoto doméstico afluente à unidade piloto do vermifiltro, a Tabela 2 apresenta os resultados referentes ao monitoramento durante o período de estudo.

Tabela 2 - Caracterização do Esgoto Afluente à Unidade Piloto ( $\mathrm{n}=29)$

\begin{tabular}{|c|c|c|c|}
\hline Variável & Média e Desvio Padrão & Variável & Média e Desvio Padrão \\
\hline $\mathrm{DQO}\left(\mathrm{mgO}_{2} / \mathrm{L}\right)$ & $524 \pm 206$ & Alcalinidade $\left(\mathrm{mgCaCO}_{3} / \mathrm{L}\right)$ & $264 \pm 55,2$ \\
\hline NTK (mgN/L) & $80 \pm 43$ & $\mathrm{pH}$ & $7,1 \pm 0,2$ \\
\hline $\mathrm{N}-\mathrm{NH}_{4}{ }^{+}\left(\mathrm{mgN}-\mathrm{NH}_{4}{ }^{+} / \mathrm{L}\right)$ & $66 \pm 9,8$ & $\mathrm{SST}(\mathrm{mg} / \mathrm{L})$ & $219 \pm 195$ \\
\hline $\mathrm{P}_{\text {total }}\left(\mathrm{mgP}-\mathrm{PO}_{4}^{-3} / \mathrm{L}\right)$ & $7,0 \pm 2,4$ & $\mathrm{SSF}(\mathrm{mg} / \mathrm{L})$ & $30 \pm 33$ \\
\hline $\mathrm{P}_{\text {sol }}\left(\mathrm{mgP}-\mathrm{PO}_{4}^{-3} / \mathrm{L}\right)$ & $5,0 \pm 2,0$ & $\mathrm{SSV}(\mathrm{mg} / \mathrm{L})$ & $189 \pm 164$ \\
\hline
\end{tabular}

Com base nessa caracterização, comparando-se os resultados médios obtidos para carga orgânica e nutrientes com os valores típicos de literatura, observa-se que os mesmos podem ser classificados como forte, e em relação aos sólidos presentes, situam-se como médios (METCALF \&
EDDY, 2004). Comparando com os trabalhos em vermifiltro dispostos na Tabela 1, a composição média do esgoto usado nesse estudo se assemeIha, em termos de DQO e SST, ao realizado por Kumar et al. (2014), apresentando, frente aos demais, concentrações mais elevadas. Deve-se res- 
saltar que o esgoto utilizado, derivado do Crusp, recebeu contribuição da cozinha e do restaurante, o que ajuda a compreender os valores superiores aos usuais para esgoto doméstico.

De uma forma geral, pode-se dizer que o processo não apresentou grandes demandas de manu- tenção ou ajustes, ficando apenas a verificação da bomba de alimentação como atividade diária. Sendo assim, foi possível operar o sistema com relativa estabilidade; a Tabela 3 apresenta uma estatística descritiva dos valores impostos em termos das variáveis operacionais.

Tabela 3 - Estatística descritiva das variáveis operacionais $(n=29)$

\begin{tabular}{|c|c|c|c|c|}
\hline & Q & $\begin{array}{l}\text { TAS - R1 } \\
\left(\mathrm{L} / \mathrm{m}^{2} . \mathrm{d}\right)\end{array}$ & $\begin{array}{c}\text { TDH - R1 } \\
\text { (h) }\end{array}$ & TDH global (d) \\
\hline Média & 36,8 & 307 & 13 & 1,4 \\
\hline Máximo & 49 & 396 & 17 & 1,7 \\
\hline Mínimo & 29 & 240 & 10 & 1,0 \\
\hline Desv. Padrão & 6,0 & 2,2 & 2,2 & 0,2 \\
\hline
\end{tabular}

Isto posto, o sistema foi mantido com uma carga orgânica média, em termos de DQQO, de $0,02 \pm 0,008 \mathrm{kgO}_{2} / \mathrm{d}$ e um carregamento superficial de $0,16 \pm 0,07 \mathrm{kgO}_{2} / \mathrm{m}^{2}$.d, valores relativamente altos quando comparado com outros processos com baixo aporte energético associados ao ecossaneamento, como as wetlands construídas (WC), os quais situam-se na faixa de 0,02 a 0,05 $\mathrm{kgO}_{2} / \mathrm{m}^{2}$.d (SILVA, 2013; ANDRADE, 2012; PLATZER, 2007; SEZERINO, 2006), evidenciando o aspecto promissor dessa tecnologia; contudo, quando comparada a TAS utilizada nesse estudo com as fornecidas na Tabela 1, apenas o trabaIho de Taylor (2003) empregou uma TAS inferior, tendo os demais estudos aplicação superficial bem maior. $O$ tamanho da unidade piloto pode ser considerado o obstáculo para o uso de TAS mais elevadas; entretanto, a alta concentração de matéria orgânica e sólidos em suspensão acabam por compensar em termos de eficiência do processo, como será visto mais adiante.

\subsection{Monitoramento do substrato e população de minhocas}

A temperatura do substrato representa importante parâmetro para a manutenção da vida das minhocas. Na Fig. 4 apresenta-se uma série histórica de cada uma dessas variáveis.

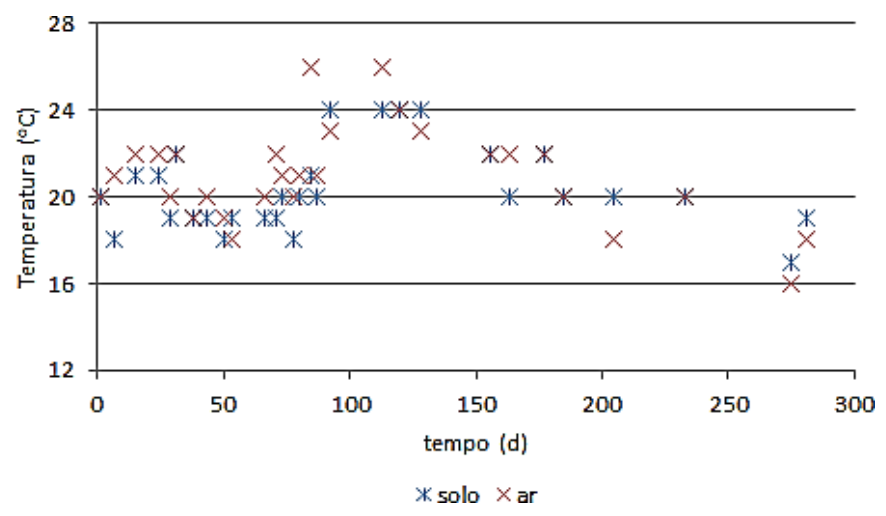

Figura 4 - Série histórica da variável temperatura (substrato/ar) 
Praticamente ao longo de todo o período de monitoramento, a temperatura do solo manteve-se próxima da temperatura do ar, proporcionando um habitat agradável para a população de minhocas. Importante destacar que não foi objetivo desse estudo avaliar a formação de vermicomposto.

Durante a operação do sistema, observou-se que o $\mathrm{pH}$ do substrato se manteve, na média, em $6,9 \pm 0,1$ e a condutividade em $292 \pm 30 \mu \mathrm{s} / \mathrm{cm}$, não gerando um estresse ambiental para a população das minhocas.

Deve-se ressaltar a necessidade de adição, por duas vezes, de novas porções de substrato em função da diminuição da camada inicial por conta de arraste.

No que diz respeito à população de minhocas, no geral se pode dizer que, em todas as observações feitas, elas aparentaram visualmente, sob o aspecto anatômico e fisiológico, estarem sadias e sem nenhuma inibição em sua mobilidade e vitalidade. No Quadro 1 tem-se a ilustração de três avaliações em diferentes momentos do monitoramento, e na Fig. 5 amostras do substrato contendo as minhocas no início da operação e no final, podendo-se observar o escurecimento na coloração do substrato, em função da aplicação do esgoto.

Quadro 1 - Monitoramento das minhocas

Data Imagem



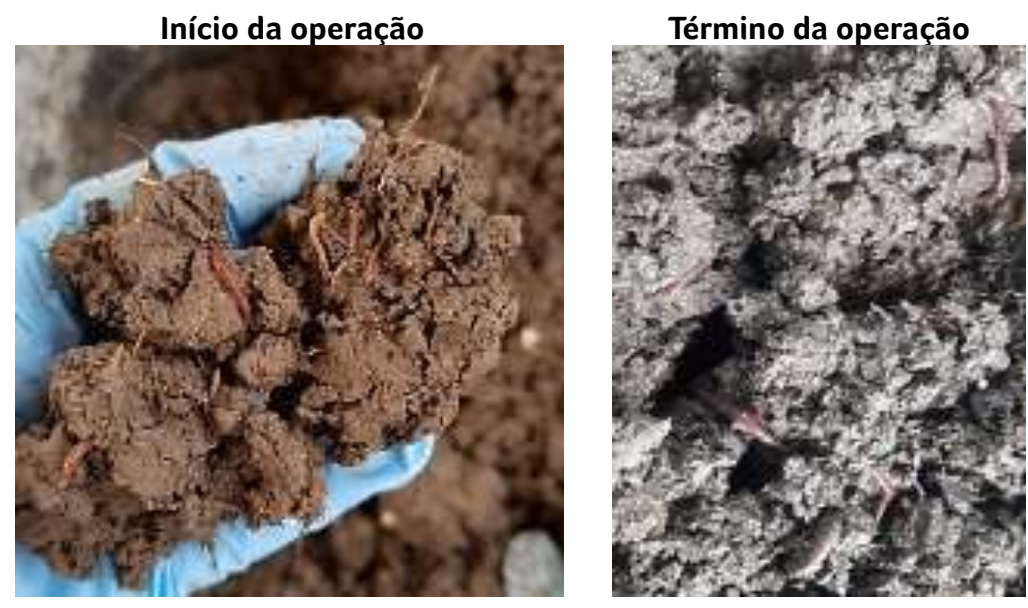

Figura 5 - Amostra do substrato contendo minhocas

\subsection{Remoção de Sólidos}

A remoção de sólidos representa uma importante etapa no tratamento de esgoto, sobretudo no eventual lançamento em corpo d'água, com vistas a evitar tanto assoreamento da calha do corpo receptor como introdução de poluentes.

Os valores obtidos de sólidos em suspensão totais (SST) no efluente final (efluente R3) da uni- dade piloto foram satisfatórios para tecnologias como a empregada no vermifiltro, oferecendo, em média, $77 \%$ de eficiência na retenção de SST do esgoto afluente, situando-se na mesma ordem de grandeza de estudos conduzidos por Xing et al. (2010), Sartori (2010) e Kumar et al. (2014), como pode ser visto na Tabela 1. A Fig. 6 apresenta a série histórica dessa variável tanto para o esgoto afluente como para o efluente final.

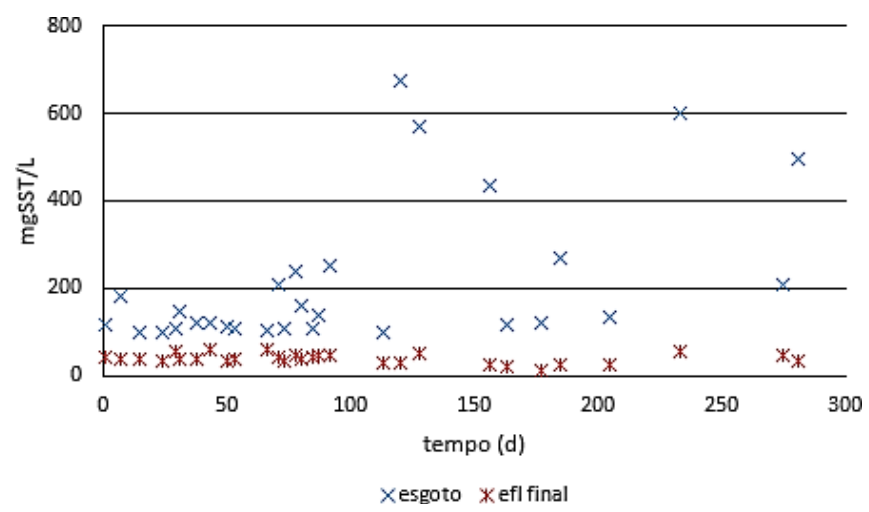

Figura 6 - Série histórica da variável SST - esgoto e efluente final (R3)

Ao longo do período de monitoramento foram feitas análises esporádicas dos efluentes provenientes dos reatores $\mathrm{R} 1$ e R2, obtendo-se, na média, respectivamente, $606 \pm 215 \mathrm{mgSST} / \mathrm{L}$ e $94 \pm 38 \mathrm{mgSST} / \mathrm{L}$, demonstrando arraste de solo verificado no reator $\mathrm{R} 1$, evidenciado pela baixa relação SSV/SST (em média 36\%), bem como a necessidade da presença dos leitos filtrantes caracterizados pelos reatores R2 e R3 como polimento à retenção de sólidos. 


\subsection{Remoção de matéria orgânica e nutrientes}

No que tange à remoção de matéria orgânica expressa em termos de DQO , o sistema demonstrou estabilidade operacional a partir do $27^{\circ} \mathrm{dia}$ de operação, mesmo frente à imposição de carga orgânica considerada alta para esgoto domés-

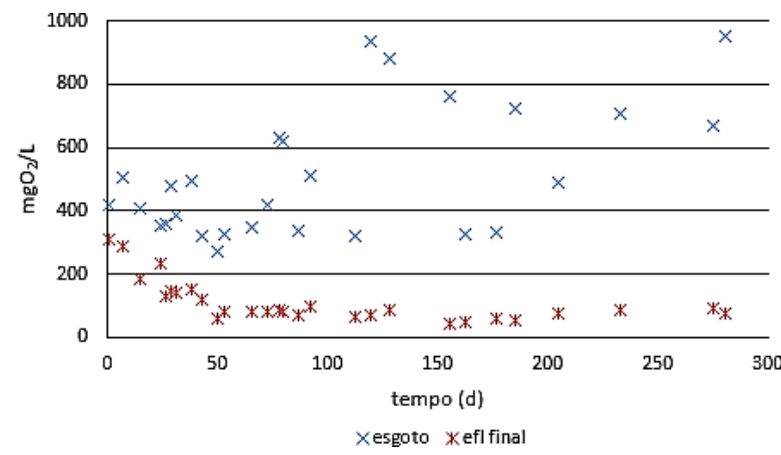

tico. A eficiência média da unidade piloto foi de $81 \%$, condizente com os estudos apresentados na Tabela 1, produzindo um efluente final (R3) com média de $\mathrm{DQO}$ de $87 \pm 31 \mathrm{mgO}_{2} / \mathrm{L}$. A Fig. 7 apresenta a série histórica dessa variável e boxplot de eficiência de remoção

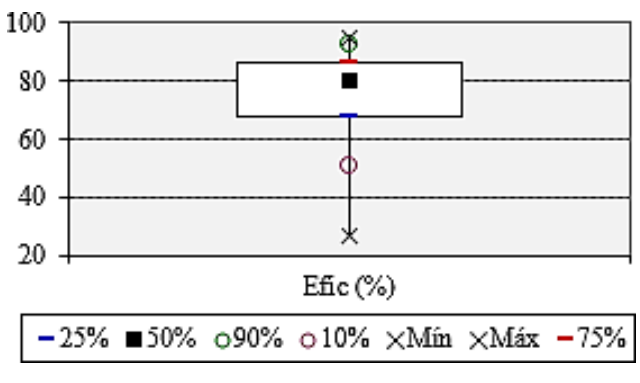

Figura 7 - Série histórica da variável DQ̣O e Box-Plot de eficiência - esgoto/efluente final (R3)

Comparando os resultados obtidos com outras tecnologias ligadas ao ecossaneamento, como as WC, verifica-se aproveitamento semelhante; diversos autores relatam terem obtidos em seus estudos eficiências médias em torno de 80\% de DQO (Silva, 2013; Almeida et al., 2010; Schirmer et al., 2009; Zanella; 2008), reforçando a assertiva de von Sperling (2005), segundo a qual sistemas como WC podem atingir até 85\% de remoção de matéria orgânica, e evidenciando o aspecto promissor associado às vantagens da vermifiltração.
O comportamento do processo frente à remoção de nitrogênio não apresentou bons índices de eficiência, obtendo-se valores médios de $56 \mathrm{mgN}-\mathrm{NH}_{3} / \mathrm{L}$ para o efluente final (R3). Os resultados nulos para as análises de nitrito e nitrato atrelados aos valores de pH (média 7,5 $\pm 0,2$ ) e alcalinidade (média $287 \pm 48,9$ ) realizadas no efluente final demonstraram a inexistência do fenômeno de nitrificação, ficando a pequena diferença entre entrada e saída (cerca de 14\%) muito por conta de outros processos menos importantes. A Fig. 8 apresenta a série histórica para a variável nitrogênio amoniacal.

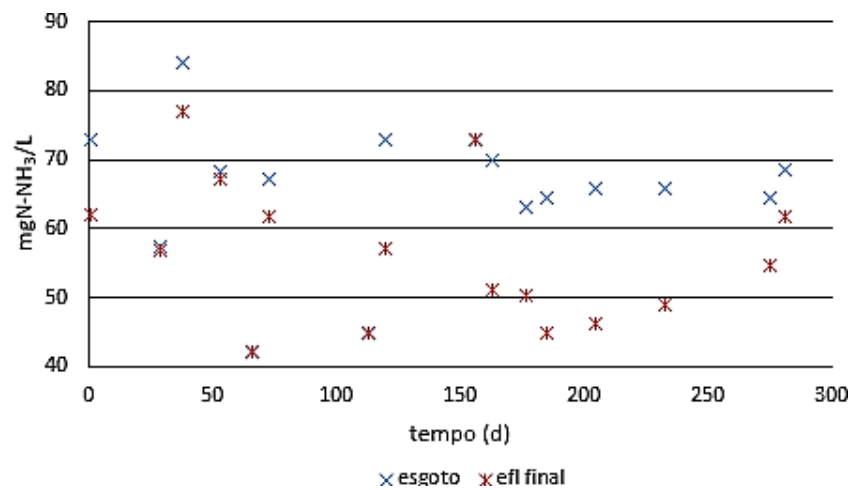

Figura 8 - Série histórica da variável - efluente final (R3) 
Em relação ao fósforo, o sistema demonstrou ser mais promissor, chegando a valores médios de $37 \%$ e $23 \%$ de eficiência para fósforo total e inorgânico, respectivamente. Obteve-se para

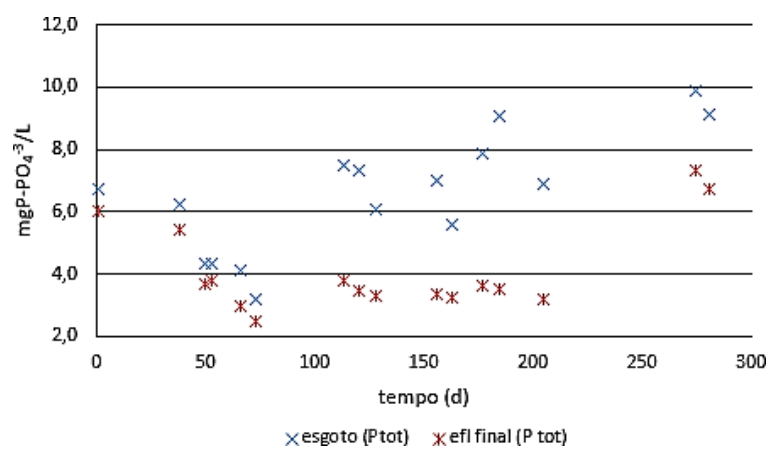

o efluente final (R3) a concentração média de $4,1 \pm 1,43 \mathrm{mgP}^{-\mathrm{PO}_{4}}{ }^{-3} / \mathrm{L}$ e $3,2 \mathrm{mgP}-\mathrm{PO}_{4}^{-3} / \mathrm{L}$ de fósforo total e fósforo solúvel (ortofosfato). A Fig. 9 ilustra a série histórica dessas duas variáveis.

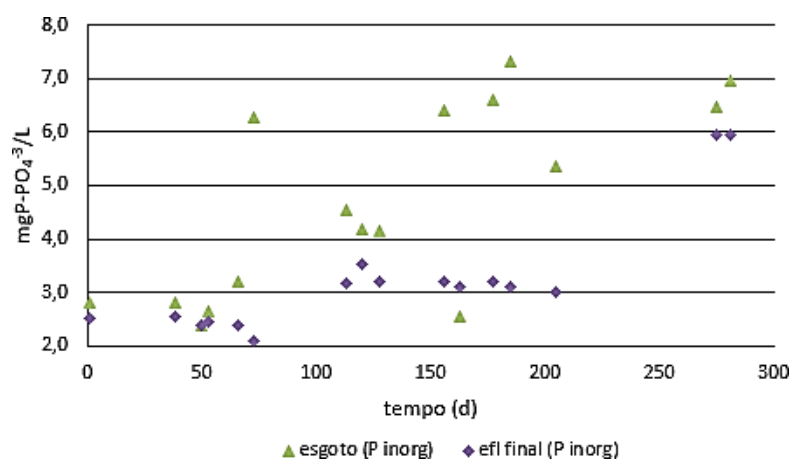

Figura 9 - Série histórica das variáveis P total e inorgânica - efluente final (R3)

A baixa eficiência observada na remoção de nutrientes pode ser explicada em função da pequena altura do substrato/leito filtrante, ocasionando baixa área de contato entre o elemento químico e o adsorvente presente nos leitos filtrantes (argila expandida e fibra de coco), ou mesmo pouca afinidade entre ambos, assim como devido aos parâmetros operacionais (TDH e TAS) aplicados. Contudo, dentro do contexto onde tal tecnologia se insere (gestão descentralizada, comunidades isoladas, zona rural), a boa eficiência na remoção de sólidos e matéria orgânica, associada à presença de nitrogênio e fósforo no efluente final, torna-a proveitosa para processos de irrigação associados à fertirrigação.

\section{CONCLUSÃO}

A unidade piloto objeto desse estudo manteve-se em operação e monitoramento por cerca de 9 meses, sendo que durante esse período o acompanhamento de parâmetros físico-químicos e biológicos, tanto do afluente como do efluente do sistema, demonstrou estabilidade e satisfatória eficiência na remoção de sólidos (média de $77 \%$ ) e matéria orgânica (média de $81 \%$ ); quanto aos nutrientes, não se observou remoção significativa de nitrogênio (média de $14 \%$ ); para o fósforo, os valores foram mais promissores (média de 37\% $\mathrm{P}$ total). A população de minhoca não sofreu inibição à presença de esgoto, mantendo-se com vitalidade e mobilidade durante todo o período.

Sob o ponto de vista das tecnologias naturais associadas ao ecossaneamento, o processo de vermifiltração demonstrou ser boa opção, na medida em que confere índices de eficiência semelhantes aos obtidos por processos do mesmo gênero, como wetlands construídas, e não apresentar demandas com o manejo de lodo ou podas de macrófitas.

A associação com leitos filtrantes em série otimiza a área necessária para instalação, além de permitir a busca por matérias adsorventes que auxiliem no polimento do tratamento. Por fim, a composição do efluente final permite inferir na possibilidade do reúso agrícola por meio da fertirrigação. 


\section{CONTRIBUIÇÃO DOS AUTORES}

Todos os autores contribuíram de forma igualitária.

\section{REFERÊNCIAS}

ALMEIDA, R.A., PITALUGA, D.P.S., REIS, R.P.A., Tratamento de esgoto doméstico por zona de raízes precedida de tanque séptico. Revista Biocências, UNITAL, vol. 16, no. 1, pp 73-81, 2010.

ANDRADE, H. H. B. Avaliação do Desempenho de Sistemas de Zona de Raízes (Wetlands Construídas) em Escala Piloto Aplicados ao Tratamento de Efluente Sintético, Dissertação (Mestrado). Universidade Tecnológica Federal do Paraná, 2012.

APHA/AWWA/WEF, Standard Methods for the Examination of Water and Wastewater, 23a Edição, Washington DC. 2017.

BOS, R. et al. Manual sobre os direitos humanos à água potável e saneamento para profissionais. London; Reino Unido: IWA Publishing, 2016.

CDESC (Committee on Economic, Social and Cultural Rights). General Comment No. 15: The Right to Water, de 20 de janeiro de 2003.

DONATI, C. et al. Microcystin-LR adsorption by powdered activated carbon. Water Research, [s. L.], v. 28, n. 08, p.1935-1742, ago. 1994.

KUMAR, T. et al. Performance evaluation of vermifilter at different hydraulic loading rate using river bed material. Ecological Engineering, [s. L.], v. 62, n. [s. L.], p.77-82, jan. 2014. https://doi. org/10.1016/j.ecoleng.2013.10.028

LO MONACO, P. A. et al. Influência da granulometria da serragem de madeira como material filtrante no tratamento de águas residuárias. Revista Brasileira de Engenharia Agrícola e Ambiental, Campina Grande, v. 08, n. 01, p.116-119, fev. 2004. http://dx.doi. org/10.1590/S1415-43662004000100017

MADRID, F. J. P. L. Aplicação da vermifiltração no tratamento de esgoto sanitário. 2016. 131 f. Dissertação (Mestrado em Engenharia Civil) - Unicamp, Campinas, 2016.

MASSCHELEIN, W. J. Unit processes in drinking water treatment. [s. L.]: Environmental Science \& Pollution, 1992.

METCALF \& EDDY, Wastewater Engineering: Treatment and Reuse. $4^{\mathrm{a}}$ edição, G. Tchobanoglous, F. L Burton, H. D. Stensel (Editores), McGraw-Hill, Nova Yorque. 2004.

NBR 7229, Projeto, construção e operação de sistemas de tanques sépticos. Associação Brasileira de Normas Técnicas (ABNT), Rio de Janeiro, 1993. Disponível em < http://www.ct.ufpb.br/ elis/SaneamentoAmbiental/ABNTNBR7229.pdf>. Acesso em 18 nov. 2018.

OLIVEIRA JÚNIOR, J. L. Tratamento descentralizado de águas residuárias domésticas: uma estratégia de inclusão social. In: LIRA, W. S.; CÂNDIDO, G. A. Gestão Sustentável dos Recursos Naturais: Uma Abordagem Participativa. Campina Grande: Eduepb, 2013.
ONU. Glossário de termos do Objetivo de Desenvolvimento Sustentável 6: Assegurar a disponibilidade e gestão sustentável da água e saneamento para todas e todos. [s. L.]: Onu, 2018.

ONU. Resolução 64/292: The human right to water and sanitation, de 28 de julho de 2010.

ONU. The human right to water and sanitation. 2014. Disponível em: <http://www.un.org/waterforlifedecade/human_right_to_ water.shtml>. Acesso em: 20 mar. 2018.

OTTERPOHL, R.; GROTTKER, M.; LANGE, J. Sustainable water and waste management in urban areas. Water Science And Technology, [s. L.], v. 35, n. 09, p.121-133, jan. 1997. https://doi. org/10.2166/WST.1997.0336

PLATZER, C., SENF, C., HOFFMANN, H., CARDIA, W., COSTA, R.H.R., Dimensionamento de wetland de fluxo vertical com nitrificação - adaptação de modelo europeu para as condições climáticas do brasil. In: $24^{\circ}$ Congresso Brasileiro de Engenharia Sanitária e Ambiental. ABES. 2007 Anais...

PNUD. 0 que é a Agenda 2030? Disponível em: <http://www. agenda2030.com.br/>. Acesso em: 20 abr. 2018.

SARTORI, Márcia Aparecida. Desempenho de vermifiltros no tratamento de esgoto doméstico em pequenas comunidades. 2010. 75 f. Dissertação (Mestrado em Engenharia Agrícola) - Universidade Federal de Viçosa, Viçosa, 2010.

SCHIRMER, Waldir Nagel et al. Tratamento de esgoto por zona de raízes em comunidade rural - Parte 2: avaliação. Rev. Acad., Ciênc. Agrár. Ambient., Curitiba, v. 7, n. 2, p.165-173, abr./jun. 2009. http://dx.doi.org/10.7213/cienciaanimal.v6i2.10460

SEZERINO, P.H., Potencialidade dos filtros plantados com macrófitas (constructed wetlands) no pós- tratamento de lagoas de estabilização sob condições de clima subtropical. Tese (Doutorado) - Universidade Federal de Santa Catarina, 2006.

SILVA, M.V., Avaliação da aplicabilidade de sistema de wetland construído híbrido no tratamento de esgoto sanitário. Trabalho de Conclusão de Curso - Centro Universitário SENAC, 2013.

SINGH, R.; BHUNIA, P.; DASH, R. R. A mechanistic review on vermifiltration of wastewater: Design, operation and performance. Elsevier- Journal Of Environmental Management, [s. L.], v. 197, n. [s. L.], p.656-672, 15 jul. 2017. https://doi.org/10.1016/j.jenvman.2017.04.042

SINHA, R. K.; BHARAMBE, G.; CHAUDHARI, U. Sewage treatment by vermifiltration with synchronous treatment of sludge by earthworms: a low-cost sustainable technology over conventional systems with potential for decentralization. Environment Systems And Decisions, [s. L.], v. 28, n. 4, p.409-420, dez. 2008. https:// doi.org/10.1007/s10669-008-9162-8

SUGIMOTO, L. Vermifiltração é alternativa para o tratamento de esgoto: Tecnologia ainda pouco conhecida alia a degradação bac- 
teriana com a vermicompostagem. Jornal da Unicamp. Campinas, p. 9-9. jun. 2016.

VON SPERLING, M. Introdução à qualidade das águas e ao tratamento de esgotos. Princípios do tratamento biológico de águas residuárias. Vol 1. 3. ed. Belo Horizonte: Departamento de Engenharia Sanitária e Ambiental, UFMG, 2005.

XING, Meiyan; LI, Xiaowei; YANG, Jian. Treatment performance of small-scale vermifilter for domestic wastewater and its relationship to earthworm growth, reproduction and enzymatic activity. African Journal Of Biotechnology, [s.l.], v. 9, n. 44, p.75137520, 1 nov. 2010.
YANG, Jian et al. Converter slag-coal cinder columns for the removal of phosphorous and other pollutants. Journal Of Hazardous Materials, [s. L.], v. 168, n. 01, p.331-337, 30 ago. 2009.

ZANELLA, L. Plantas ornamentais no pós-tratamento de efluentes sanitários: wetlands-construídos utilizando brita e bambu como suporte. Tese (Doutorado em Engenharia Civil, Arquitetura e Urbanismo) - Unicamp, 2008,

ZHAO, L. et al. Earthworm-microorganism interactions: A strategy to stabilize domestic wastewater sludge. Water Research, [s.l.], v. 44, n. 8, p.2572-2582, abr. 2010. Elsevier BV. http://dx.doi.org/10.1016/j.watres.2010. http://dx.doi.org/10.1016/j.watres.2010 